\title{
Analisis Keterlambatan Proyek Jalur Pejalan Kaki (Studi Kasus: Jalur Pedestrian Jalan Kandang Roda - Pakansari)
}

\author{
Rosa Kartika Maharani1, Yunita Dian Suwandari2 \\ ${ }^{1}$ Program Studi Teknik Sipil, Fakultas Teknik, Universitas Mercu Buana \\ ${ }^{2}$ Program Studi Teknik Sipil, Fakultas Teknik, Universitas Mercu Buana \\ Email: ${ }^{1}$ rosamaharani28@gmail.com,${ }^{2}$ yunita.dian@mercubuana.co.id
}

\begin{abstract}
The purpose of Kandang Roda - Pakansari Pedestrian Project is to supporting pedestrians to be more comfortable, safe and also to make the face of the capital city of Bogor Regency be more attractive for tourism. The purpose of research is to identify major factors that contribute the most on project delays. The research is using quantitative methods and questionnaire towards the employee of DINAS PUPR Bogor Regency as the owner and the employee of PT. Vanca Utama Perkasa as the main contractors. The questionnaire will be collected using SPSS software. The research is required to avoid similar fault and causing many loss. The results of research said that Environment Factor (X.6) is being the major factor that affect delays on this project according to Statistic Descriptive Analysis test. The factor had 4.00 mean bigger than others, with Availability of utilities (cables); PLN, Telkom, PDAM, Fiber Optic which are underground as the indicato (X6.11). The result is support by $T$ Test with a probability value of 0.0000 which means that partially there is a significant influence between these variables and project delays.
\end{abstract}

Keywords: Delays, Project, Quantitative, Questionmaire, SPSS

\begin{abstract}
Abstrak
Proyek Jalur Pedesrtian Jalan Kandang Roda - Pakansari adalah proyek yang dibangun dengan tujuan untuk menunjang para pejalan kaki agar dapat lebih nyaman, aman dan juga membuat wajah ibu kota Kabupaten Bogor menarik bagi wisatawan. Penelitian ini bertujuan untuk mengidentifikasi faktor-faktor apa saja yang paling berkontribusi terhadap keterlambatan pelaksanaan proyek. Metode penelitian yang digunakan adalah pendekatan kuantitatif dengan penyebaran kuesioner yang dilakukan terhadap karyawan di DINAS PUPR Kabupaten Bogor selaku owner dan karyawan di PT. Vanca Utama Perkasa, selaku kontraktor utama yang kemudian data-data yang diperoleh akan diolah menggunakan software SPSS. Kajian ini dilakukan agar tidak terjadi kesalahan yang sama pada waktu berikutnya. Hasil penelitian menyebutkan bahwa Faktor Lingkungan (X6) menjadi faktor penyebab keterlambatan paling dominan melalui pengujian analisis statistic deskriptif dengan mean paling besar 4.0 dengan indikator Terdapatnya utilitas (kabel-kabel); PLN, Telkom, PDAM, Fiber Optic yang berada dibawah tanah (X6.11). Hasil ini didukung dengan pengujian Uji T dengan nilai probabilitas sebesar 0,0000 yang artinya secara parsial ada engaruh signifikan antara variabel tersebut dengan keterlambatan proyek.
\end{abstract}

Keywords: Keterlambatan, Kuantitatif, Kuesioner, Proyek, SPSS

\section{Pendahuluan}

Jalur pedestrian adalah ruang luar yang dapat digunakan untuk kegiatan penduduk kota seharihari. [1](Pratitis 2015) mengatakan daerah jalur pejalan kaki memiliki banyak fungsi, salah satu fungsi mereka baik sebagai fasilitas untuk pejalan kaki, juga sebagai ruang terbuka untuk berbagai aktifitas diantaranya aktifitas sosial dan juga aktifitas lainnya. Berbagai aktifitas tersebut contohnya adalah untuk kegiatan berjalan-jalan, melepas lelah, duduk santai, tempat kampanye, upacara resmi dan sebagai tempat berdagang. Jalur pedestrian sudah seharusnya dapat menjadi fasilitas yang baik yang disediakan baik oleh pemerintah maupun lembaga swasta sebagai fasilitas untuk pejalan kaki.

Dalam upaya untuk meningkatkan pembangunan dan pertumbuhan Kabupaten Bogor, Pemerintah Kabupaten (Pemkab) Bogor mencanangkan program Panca Karsa yaitu lima keinginan atau cita-cita diantaranya Bogor membangun, Bogor sehat, Bogor cerdas, Bogor maju dan Bogor berkeadaban. Salah satu dari realisasi program tersebut adalah pembangunan infrastruktur. 
Proyek Jalur Pedestrian Jalan Kandang Roda - Pakansari merupakan bagian dari upaya Pemkab Bogor untuk menunjang para pejalan kaki agar dapat lebih nyaman dan aman. Selain itu, pembangunan pedestrian ini juga merupakan upaya untuk mempercantik wajah ibu kota sehingga menarik para wisatawan.

Proyek Jalur Pedestrian Jalan Kandang Roda - Pakansari merupakan proyek dibawah koordinasi Dinas PUPR dengan pelaksana dari PT. Vanca Utama Perkasa memiliki panjang total 832 m. Pembangunan telah dilaksanakan dari tahun 2020 dan sesuai perencanaaan akan selesai pada akhir tahun 2020. Namun pada pelaksanaan proyek konstruksi sering mengalami kendala pada proses pekerjaan. Kendala tersebut menjadi penyebab terlambatnya pelaksanaan proyek, sehingga proyek tersebut tidak berlangsung sesuai rencana. Keterlambatan pekerjaan konstruksi baik pada pekerjaan konstruksi jalan maupun pekerjaan lainnya tidak dapat dihindari, sehingga diperlukan kemampuan manajerial yang baik bagi pihak yang terlibat didalam proses konstruksi.(Palulun, Pratasis, and Mangare 2017).

Proyek Jalur Pedestrian Jalan Kandang Roda - Pakansari ini merupakan proyek sebesar Rp 24.986.150.00,00 yang mengalami keterlambatan pada pekerjaannya. Proyek ini seharusnya dapat terselesaikan dalam waktu 110 hari kalender sesuai kontrak kerja, namun sampai dengan saat ini proyek belum selesai.

Oleh karena itu perlu mencari faktor penyebab dan faktor dominan terjadinya keterlambatan dalam pelaksanaan proyek ini untuk untuk mencari solusi alternatif dari permasalahan yang terjadi. Dengan demikian diharapkan dapat menoptimalkan proses penyelesaian proyek.

\section{Metode}

Metode penelitian merupakan suatu cara alamiah untuk memperoleh data dengan kegunaan dan tujuan tertentu. Metode yang digunakan dalam penelitian ini adalah metode penelitian kuantitatif. Penelitian kuantitatif adalah penelitian penelitian ilmiah yang sistematis terhadap bagian-bagian dan fenomena serta hubungan-hubungannya. Dalam bab ini akan dijelaskan lebih spesifik tentang metode penelitian yang di gunakan untuk mengetahui faktor-faktor penyebab keterlambatan pelaksanaan Proyek Jalur Pedestrian Jalan Kandang Roda - Pakansari.

Penelitian kali ini dilakukan secara deskriptif kuantitatif yang di dapatkan melalui wawancara responden kepada pakar di bidangnya dan pengisian kuisioner. Daftar pertanyaan atau kuisioner tersebut di bagikan kepada responden untuk diisi, dari rekapitulasi validasi pakar pada kuisioner tahap pertama di dapat beberapa indikator yang relevan dan terdapat beberapa indikator yang menurut para pakar tidak berpengaruh terhadap keterlambatan Proyek Jalur Pedestrian Jalan Kandang Roda Pakansari. Selanjutnya variabel yang tidak berpengaruh tersebut di eleminiasi dan tidak masuk dalam penyebaran kuesioner tahap dua nanti, sehingga untuk selanjutnya indikator yang dipakai ada beberapa indikator untuk variabel independen (X), dengan kode yang telah disesuaikan, serta ditambah 1 indikator untuk variabel dependen (Y). Setelah dilakukan validasi hasil kuesioner para pakar, pada tahap ini pengumpulan data dilakukan dengan memberikan atau menyebarkan angket kuesioner tahap 2.

\section{Hasil dan Pembahasan}

Penelitian ini bertujuan untuk mengetahui penyebab keterlambatan pada Proyek Jalur Pedestrian Jalan Kandang Roda - Pakansari, mengetahui pengaruh faktor tenaga kerja, material, alat, keuangan, perubahan desain dan metode, lingkungan, organisasi, kontrak, force majeur dan pengawasan terhadap terhadap pelaksanaan pekerjaan, juga mengetahui faktor variabel yang paling dominan pengaruhnya terhadap proyek tersebut. Adapun uji instrumen pada penelitian kali ini menggunakan SPSS Versi 25, analisis statistik deskriptif, uji validitas, uji reliabilitas, uji normalitas, uji analasis regresi linier berganda, uji t dan uji F. 


\section{Analisis Statistik Deskriptif}

Tabel 1. Hasil Analisis Deskriptif

Statistics

\begin{tabular}{|c|c|c|c|c|c|c|c|c|}
\hline \multicolumn{9}{|c|}{ Statistics } \\
\hline & \multicolumn{2}{|c|}{$\mathrm{N}$} & \multirow[b]{2}{*}{ Mean } & \multirow{2}{*}{$\begin{array}{c}\text { Std. } \\
\text { Deviation }\end{array}$} & \multirow[b]{2}{*}{ Variance } & \multirow[b]{2}{*}{ Min } & \multirow[b]{2}{*}{ Max } & \multirow[b]{2}{*}{$\underline{\text { Sum }}$} \\
\hline & Valid & Missing & & & & & & \\
\hline X3.1 & 30 & 0 & 3.97 & 0.718 & 0.516 & 3 & 5 & 119 \\
\hline X4.4 & 30 & 0 & 3.97 & 0.765 & 0.585 & 3 & 5 & 119 \\
\hline X4.6 & 30 & 0 & 3.67 & 0.959 & 0.920 & 1 & 5 & 110 \\
\hline $\mathrm{X} 4.7$ & 30 & 0 & 3.63 & 0.890 & 0.792 & 2 & 5 & 109 \\
\hline $\mathrm{X} 4.8$ & 30 & 0 & 3.97 & 0.615 & 0.378 & 3 & 5 & 119 \\
\hline X5.1 & 30 & 0 & 3.73 & 0.980 & 0.961 & 1 & 5 & 112 \\
\hline X5.5 & 30 & 0 & 3.93 & 1.015 & 1.030 & 1 & 5 & 118 \\
\hline X6.1 & 30 & 0 & 3.57 & 1.006 & 1.013 & 1 & 5 & 107 \\
\hline X6.4 & 30 & 0 & 3.97 & 0.890 & 0.792 & 2 & 5 & 119 \\
\hline X6.9 & 30 & 0 & 3.97 & 0.850 & 0.723 & 2 & 5 & 119 \\
\hline X6.10 & 30 & 0 & 3.67 & 0.884 & 0.782 & 2 & 5 & 110 \\
\hline X6.11 & 30 & 0 & 4.00 & 0.871 & 0.759 & 2 & 5 & 120 \\
\hline X8.13 & 30 & 0 & 3.77 & 0.774 & 0.599 & 3 & 5 & 113 \\
\hline X9.2 & 30 & 0 & 3.93 & 0.785 & 0.616 & 3 & 5 & 118 \\
\hline Total & 30 & 0 & 53.73 & 6.958 & 48.409 & 44 & 70 & 1612 \\
\hline
\end{tabular}

Berdasarkan data di atas, indikator yang memiliki skor tertinggi yaitu pada kategori Faktor Lingkungan untuk indicator X6.11 "Terdapatnya utilitas (kabel-kabel); PLN, Telkom, PDAM, Fiber Optic) yang berada dibawah tanah" dengan skor total 120 dan rata-rata 4.00, hal ini menyimpulkan bahwa berdasarkan analisis statistic deskriptif, faktor paling dominan yang menyebabkan keterlambatan Proyek Jalur Pedestrian Jalan Kandang Roda - Pakansari adalah faktor lingkungan.

\section{Uji Validitas}

Tabel 2. Hasil Uji Validitas

\begin{tabular}{|c|c|c|c|c|}
\hline No & Faktor & $\begin{array}{c}\text { Nilai Corrected } \\
\text { Item }\end{array}$ & Nilai r-tabel & Kesimpulan \\
\hline 1. & Faktor Alat (X3) & $\begin{array}{c}\mathrm{X} 3.1=1.000 \\
\mathrm{X} 3 \text { Total }=1.000\end{array}$ & 0,361 & Valid \\
\hline 2. & Faktor Keuangan (X4) & $\begin{array}{c}X 4.4=0.445 \\
X 4.8=0.628 \\
X 4.6=0.835 \\
X 4.7=0.818 \\
X 4 \text { Total }=1.000\end{array}$ & 0,361 & Valid \\
\hline 3. & $\begin{array}{c}\text { Faktor Perubahan Design / } \\
\text { Metode (X5) }\end{array}$ & $\begin{array}{c}X 5.1=0.892 \\
X 5.5=0.900 \\
\text { X5 Total }=1.000\end{array}$ & 0,361 & Valid \\
\hline 4. & Faktor Lingkungan (X6) & $\begin{array}{c}\text { X6.1 }=0.711 \\
\text { X6.10 }=0.768 \\
\text { X6.4 }=0.699 \\
\text { X6 Total }=1.000 \\
\text { X6.9 }=0.781\end{array}$ & 0,361 & Valid \\
\hline 5. & $\begin{array}{c}\text { Faktor Perubahan Kontrak } \\
\text { Administrasi (X8) }\end{array}$ & $\begin{array}{c}\mathrm{X} 8.13=1.000 \\
\mathrm{X} 8 \text { Total }=1.000\end{array}$ & 0,361 & Valid \\
\hline 6. & Faktor Force Majeur (X9) & $\begin{array}{c}X 9.2=1.000 \\
\text { X9 Total }=1.000\end{array}$ & 0,361 & Valid \\
\hline
\end{tabular}


Dari hasil uji validitas pada Tabel 2 dapat disimpulkan bahwa setiap indikator memiliki nilai Total Correlation yaitu $X=1.000>$ dari nilai $r$-tabel $=0.361$, maka dapat disimpulkan bahwa indikator tersebut dinyatakan valid.

\section{Uji Reliabilitas}

Pada penelitian ini, setelah diuji validitasnya maka item-item yang gugur dibuang dan item yang tidak gugur dimasukkan ke dalam uji reliabilitas. Maka yang akan dihitung ada sebanyak 14 indikator $(\mathrm{N}$ of Item $=14$ ). Hasil uji reliabilitas dapat dilihat pada tabel berikut.

\section{Tabel 3. Hasil Pengujian Reliabilitas \\ Reliability Statistics

$\frac{\text { Cronbach's Alpha }}{0.844} \frac{\text { N of Items }}{14}$

Hasil uji reliabilitas didapat nilai Cronbach's Alpha sebesar rata-rata lebih dari nilai $r$ tabel pada pengujian validitas $>0.361$. Maka dapat disimpulkan bahwa instrumen dalam penelitian ini reliabel atau konsisten.

\section{Uji Normalitas}

Uji normalitas bertujuan untuk mengetahui apakah nilai residual berdistribusi normal atau tidak. Model regresi yang baik adalah memiliki residual yang berdistribusi normal.

Dasar pengambilan keputusan

- Jika nilai signifikansi > 0.05 maka nilai residual berdistribusi normal.

- Jika nilai signifikansi < 0.05 maka nilai residual berdistribusi tidak normal.

Tabel 4. Hasil Uji Normalitas Kolmogrov-Smirnov

\begin{tabular}{|c|c|c|}
\hline \multicolumn{3}{|c|}{ One-Sample Kolmogorov-Smirnov Test } \\
\hline \multirow[b]{2}{*}{$\mathrm{N}$} & \multirow[b]{3}{*}{ Mean } & \multirow{2}{*}{$\begin{array}{l}\begin{array}{c}\text { Unstandardized } \\
\text { Residual }\end{array} \\
30\end{array}$} \\
\hline & & \\
\hline & & 0.0000000 \\
\hline Normal & Std. & \\
\hline \multirow[t]{2}{*}{ Parameters ${ }^{\mathrm{a}, \mathrm{b}}$} & Deviation & 0.24181555 \\
\hline & Absolute & 0.099 \\
\hline \multirow{2}{*}{$\begin{array}{l}\text { Most Extreme } \\
\text { Differences }\end{array}$} & Positive & 0.099 \\
\hline & Negative & -0.053 \\
\hline \multicolumn{2}{|l|}{ Test Statistic } & 0.099 \\
\hline \multicolumn{2}{|c|}{ Asymp. Sig. (2-tailed) } & $.200^{\mathrm{c}, \mathrm{d}}$ \\
\hline \multicolumn{3}{|c|}{ a. Test distribution is Normal. } \\
\hline \multicolumn{3}{|c|}{ b. Calculated from data. } \\
\hline \multicolumn{3}{|c|}{ c. Lilliefors Significance Correction. } \\
\hline d. This is a lower b & and of the $t$ & ficance. \\
\hline
\end{tabular}

Berdasarkan hasil uji normalitas diketahui nilai signifikansi $0.200>0.05$ maka dapat disimpulkan bahwa nilai residual berdistribusi normal. 


\section{Analisis Regresi Linear Berganda}

Analisis ini untuk mengetahui arah hubungan antara variabel independent dengan variabel dependent apakah masing-masing variabel independent berhubungan positif atau negatif dan untuk memprediksi nilai dari variabel dependen apabila nilai variabel independent mengalami kenaikan atau penurunan. Persamaan regresi linear berganda sebagai berikut:

$Y^{\prime}=a+b 1 X 1+b 2 X 2+\ldots \ldots .+b n X r$

Keterangan:

$\mathrm{Y}^{\prime} \quad=$ Variabel dependent (nilai yang diprediksikan)

$\mathrm{X} 1$ dan $\mathrm{Xn} \quad=$ Variabel independent

a $\quad=$ Konstanta (nilai $Y^{\prime}$ apabila X1, X2 . Xn =0)

$\mathrm{b}=$ Koefisien regresi (nilai peningkatan ataupun penurunan)

Hasil analisis regresi linier berganda dapat dilihat dalam tabel berikut;

Tabel 5. Hasil Analisis Regresi Linear Berganda

Berdasarkan Kelompok Faktor Keterlambatan

\begin{tabular}{|c|c|c|c|c|c|c|}
\hline & & & Coeffic & ents $^{a}$ & & \\
\hline & & $\begin{array}{r}\text { Unstan } \\
\text { Coef }\end{array}$ & $\begin{array}{l}\text { ardized } \\
\text { ients }\end{array}$ & $\begin{array}{c}\text { Standardized } \\
\text { Coefficients }\end{array}$ & & \\
\hline & del & B & $\begin{array}{l}\text { Std. } \\
\text { Error }\end{array}$ & Beta & $\underline{\mathrm{t}}$ & $\underline{\text { Sig. }}$ \\
\hline & (Constant) & 0.085 & 0.515 & & 0.166 & 0.870 \\
\hline & Total_X3 & -0.021 & 0.100 & -0.023 & -0.213 & 0.833 \\
\hline & Total_X4 & -0.002 & 0.037 & -0.005 & -0.041 & 0.967 \\
\hline & Total_X5 & 0.072 & 0.041 & 0.195 & 1.759 & 0.092 \\
\hline & Total_X6 & 0.100 & 0.025 & 0.502 & 4.057 & 0.000 \\
\hline & Total_X8 & 0.372 & 0.120 & 0.436 & 3.093 & 0.005 \\
\hline 1 & Total_X9 & 0.014 & 0.102 & 0.016 & 0.136 & 0.893 \\
\hline
\end{tabular}

Persamaan regresinya sebagai berikut:

$Y^{\prime}=a+B 1 X 1+B 2 X 2+B 3 X 3+\ldots \ldots . .+B n X n$

$Y^{\prime}=0,085-0,021 X 3-0,002 X 4+0,072 X 5+0,100 X 6+0,372 X 8+0,014 X 9$

Keterangan:

$\mathrm{Y}^{\prime} \quad=$ Keterlambatan Proyek

a $\quad=$ Konstanta

$\mathrm{B} 1, \mathrm{~B} 2=$ koefisien regresi

$\mathrm{X} 1=$ Variabel

$\mathrm{X} 1=$ Variabel 


\section{Uji T}

Jika nilai t-hitung lebih besar dari nilai dari nilai t-tabel $(2,064)$, maka variabel bebas sendiri berpengaruh terhadap keterlambatan proyek. Hasil uji T dapat dilihat pada tabel berikut;

Tabel 6. Hasil Uji T Berdasarkan Variabel Faktor Keterlambatan

\begin{tabular}{|c|c|c|c|c|c|c|}
\hline \multicolumn{7}{|c|}{ Coefficients $^{\mathrm{a}}$} \\
\hline & & \multicolumn{2}{|c|}{$\begin{array}{c}\text { Unstandardized } \\
\text { Coefficients }\end{array}$} & \multirow{2}{*}{$\begin{array}{l}\text { Standardized } \\
\text { Coefficients } \\
\text { Beta }\end{array}$} & \multirow[b]{2}{*}{$\mathrm{t}$} & \multirow[b]{2}{*}{ Sig. } \\
\hline \multicolumn{2}{|c|}{ Model } & $\mathrm{B}$ & Std. Error & & & \\
\hline & $\begin{array}{l}\text { (Constan } \\
\text { t) }\end{array}$ & 0.085 & 0.515 & & 0.166 & 0.870 \\
\hline & Total_X & & & & - & \\
\hline & 3 & -0.021 & 0.100 & -0.023 & 0.213 & 0.833 \\
\hline & Total_X & & & & - & \\
\hline & 4 & -0.002 & 0.037 & -0.005 & 0.041 & 0.967 \\
\hline & Total_X & & & & & \\
\hline & 5 & 0.072 & 0.041 & 0.195 & 1.759 & 0.092 \\
\hline & Total_X & & & & & \\
\hline & 6 & 0.100 & 0.025 & 0.502 & 4.057 & 0.000 \\
\hline & Total_X & & & & & \\
\hline & & 0.372 & 0.120 & 0.436 & 3.093 & 0.005 \\
\hline & Total_X & & & & & \\
\hline 1 & $9-$ & 0.014 & 0.102 & 0.016 & 0.136 & 0.893 \\
\hline
\end{tabular}

Dari tabel 6 dapat disimpulkan jika hasil dari uji t dapat dilihat bahwa terdapat variabel independen yang berpengaruh signifikan secara parsial terhadap variabel dependen yaitu X6 dan X8 atau secara variabel yaitu Faktor Lingkungan dan Faktor Kontrak dan Administrasi.

\section{Uji F}

Penentuan hasil uji f dapat dilihat jika nilai f-hitung lebih besar dari f-tabel maka variabel bebas secara bersama - sama berpengaruh pada keterlambatan proyek.

\section{Tabel 7. Hasil Uji F}

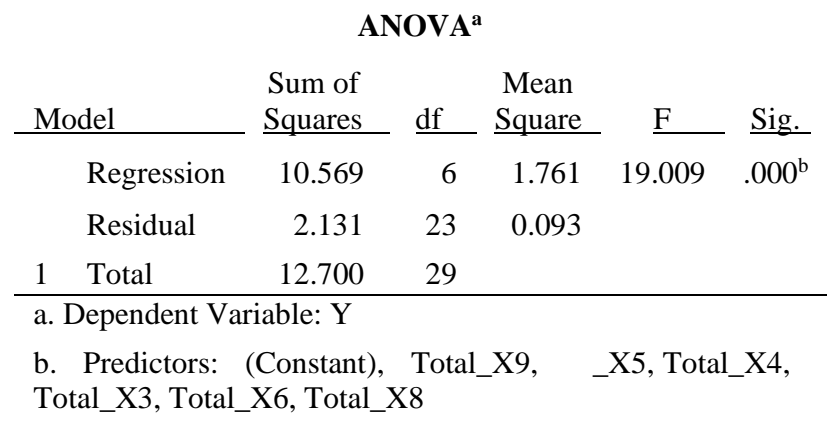

Karena F hitung > F tabel $(19,009>2,25)$, maka Ho diterima, artinya variabel bebas dalam penelitian ini secara bersama - sama mempengaruhi keterlambatan proyek. Jadi dari kasus ini dapat disimpulkan bahwa $\mathrm{X} 1, \mathrm{X} 2, \mathrm{X} 3 \ldots \mathrm{Xn}$ secara simultan berpengaruh terhadap Y.

\section{Analisis Determinasi (R2)}

Dalam pengukurannya koefisien determinasi mempunyai rentang 0\% - 100\%. Jika dalam suatu penelitian didapatkan nilai variabel yang kecil maka kemampuan variabel bebas dalam penelitian tersebut sangat lemah dalam mempengaruhi variabel terikat. Jika nilai koefisian determinasi mendekati $100 \%$ artinya variabel bebas yang ada dalam penelitian tersebut mempunyai pengaruh 
yang besar terhadap variabel terikat. Dari hasil analisis regresi, lihat pada output model summary dan disajikan sbb:

\section{Tabel 8. Hasil Analisis Regresi}

\begin{tabular}{|c|c|c|c|c|}
\hline \multicolumn{5}{|c|}{ Model Summary ${ }^{b}$} \\
\hline Model & $\underline{\mathrm{R}}$ & $\begin{array}{c}\mathrm{R} \\
\text { Square }\end{array}$ & $\begin{array}{l}\text { Adjusted } \\
\text { R Square }\end{array}$ & $\begin{array}{l}\text { Std. Error of the } \\
\text { Estimate }\end{array}$ \\
\hline 1 & $.912^{\mathrm{a}}$ & 0.832 & 0.788 & 0.304 \\
\hline
\end{tabular}

Berdasarkan tabel diperoleh angka R2 (R Square) sebesar 0.788 atau 78,8 \%. Hal ini menunjukkan bahwa persentase sumbangan pengaruh variabel independen $(\mathrm{X} 1, \mathrm{X} 2, \ldots \mathrm{Xn})$ terhadap variabel dependen (keterlambatan proyek ) sebesar 78,8\%. Atau variasi variabel independen yang digunakan dalam model (X1, X2,Xn) mampu menjelaskan sebesar 78,8\% variabel dependen (keterlambatan proyek) atau mengandung arti bahwa pengaruh variabel $\mathrm{X} 1, \mathrm{X} 2, \ldots \mathrm{Xn}$ secara simultan terhadap variabel Y. Sedangkan sisanya sebesar 21,2\% dipengaruhi atau dijelaskan oleh variabel lain yang tidak dimasukkan penelitian ini.

\section{Kesimpulan}

Berdasarkan hasil penelitian dan pembahasan yang telah diuraikan pada bab sebelumnya, maka diperoleh kesimpulan sebagai berikut.

Faktor-faktor yang menyebabkan keterlambatan Proyek Jalur Pedestrian Jalan Kandang Roda - Pakansari adalah Faktor Alat, Faktor Keuangan, Faktor Perubahan Design / Metode, Faktor Lingkungan, Faktor Kontrak Administrasi, dan Faktor Force Majeur.

Dari variabel utama penyebab keterlambatan proyek Proyek Jalur Pedestrian Jalan Kandang Roda - Pakansari tersebut faktor yang paling dominan berdasarkan nilai mean analisis statistik deskriptif tertingi tertinggi 4.00 yaitu Faktor Lingkungan dengan indikator paling berpengaruh yaitu "Terdapatnya utilitas (kabel-kabel); PLN, Telkom, PDAM, Fiber Optic) yang berada dibawah tanah atau X6.11", pernyataan ini di dukung oleh hasil pengujian analisis regresi berganda, berdasarkan hasil pengujian tersebut nilai koefisien regresi positif artinya ada pengaruh variabel terhadap keterlambatan proyek. Faktor ini didukung berdasarkan hasil Uji T dengan nilai probablilitas sebesar 0,000 yang artinya secara parsial ada pengaruh signifikan antara variabel tersebut dengan keterlambatan proyek.

Solusi alternatif penyelesaian terhadap faktor paling dominan penyebab keterlambatan: "Terdapatnya utilitas (kabel-kabel) yang berada dibawah tanah" adalah perlunya dilakukan koordinasi dengan stakeholder terkait agar pelaksanaan pekerjaan tidak tumpang tindih dan blue print utilitas bawah tanah dapat digunakan gunakan untuk antisipasi.

\section{Referensi}

[1] A.- Pratitis, "Kajian Perkembangan Aktivitas Sosial dan Rekreasi di Jalur Pedestrian (Studi Kasus : Jalur Pedestrian Jalan Pahlawan)," J. Pembang. Wil. Kota, vol. 11, no. 2, p. 129, 2015, doi: 10.14710/pwk.v11i2.10843. 